\title{
Low concentrations of trichosanthin induce apoptosis and cell cycle arrest via c-Jun N-terminal protein kinase/mitogen-activated protein kinase activation
}

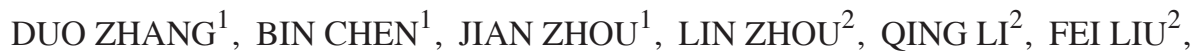 \\ KUANG-YEN CHOU ${ }^{2}$, LEI TAO ${ }^{1}$ and LI-MING LU ${ }^{2}$ \\ ${ }^{1}$ Department of Otolaryngology-Head and Neck Surgery, Eye, Ear, Nose and Throat Hospital, \\ Fudan University School of Medicine, Shanghai 200031; ${ }^{2}$ Shanghai Institute of Immunology, \\ Shanghai Jiaotong University School of Medicine, Shanghai 200025, P.R. China
}

Received February 3, 2014; Accepted October 14, 2014

DOI: $10.3892 / \mathrm{mmr} .2014 .2760$

\begin{abstract}
Trichosanthin (TCS) is a type I ribosomeinactivating protein, which inhibits cell viability in human epithelial type 2 (HEp-2) and AMC-HN-8 human laryngeal epidermoid carcinoma cells. Although TCS is a potential chemotherapeutic agent, its mechanism of action remains to be elucidated. In the present study, HEp-2 and AMC-HN-8 cells were treated with different concentrations of TCS combined with or without cisplatin. After 5 days of successive treatment, different experimental groups were detected using a cell counting kit- 8 and the collected supernatants were analyzed using a lactate dehydrogenase kit. Flow cytometric assays were performed to detect apoptosis and cell cycle arrest in the HEp-2 and AMC-HN-8 cells, reverse transcription quantitative polymerase chain reaction was performed to detect the levels of $\mathrm{p} 27, \mathrm{p} 21^{\mathrm{WAF}}$ and western blot analysis was performed to detect changes in c-Jun $\mathrm{N}$-terminal protein kinase (JNK)/phosphorylated (phospho)-JNK, p38/phospho-p38, extracellular signal-regulated kinase (ERK)/phospho-ERK, caspase- 3 and caspase- 9 in the HEp- 2 and AMC-HN-8 cancer
\end{abstract}

Correspondence to: Professor Lei Tao, Department of Otolaryngology-Head and Neck Surgery, Eye, Ear, Nose and Throat Hospital, Fudan University School of Medicine, 83 Fenyang Road, Shanghai 200031, P.R. China

E-mail: doctortaolei@163.com

Professor Li-Ming Lu, Shanghai Institute of Immunology, Shanghai Jiaotong University School of Medicine, 280 South Chongqing Road, Shanghai 200025, P.R. China

E-mail: lulunew2003@163.com

Abbreviations: TCS, trichosanthin; MAPK, mitogen-activated protein kinase; JNK, c-Jun N-terminal protein kinase; LDH, lactate dehydrogenase.

Key words: TCS, apoptosis, human epithelial type 2, AMC-HN-8, JNK/MAPK, SP600125 cells. TCS significantly inhibited the cell viability of the HEp-2 and AMC-HN-8 cells, independently of necrosis. TCS induced apoptosis and increased the percentage of HEp-2 and AMC-HN-8 cells in the S-phase of the cell cycle. In addition, the JNK/mitogen-activated protein kinase (MAPK) pathway was activated by TCS in the HEp-2 and AMC-HN-8 cells. Low concentrations of TCS also induced apoptosis and S-phase cell cycle arrest in the HEp-2 and AMC-HN-8 cells. The antitumor effects of TCS may be associated with JNK/MAPK activation.

\section{Introduction}

Trichosanthin (TCS) is a protein isolated from the root of the tuber Trichosanthes kirilowii, which has been widely used in traditional Chinese medicine. TCS, a $27 \mathrm{kDa}$ protein consisting of 247 amino acid residues, is a member of the type I ribosome-inactivating protein family (1). Pharmacological studies have demonstrated that TCS exhibits a broad spectrum of biological and pharmacological activities, including abortifacient, anti-human immunodeficiency virus (HIV), immunomodulatory and antitumor activities (2-5).

TCS has been demonstrated to be effective in treating chorionic epithelioma in vitro (3). Cancer cell line studies have indicated that TCS interferes with cell growth and causes apoptosis in cervical carcinoma HeLa cells, leukemia K562 and HL60 cells, gastric carcinoma MKN-45 cells and nasopharyngeal cancer CNE-1 cells $(2,4)$. Several studies have also demonstrated that TCS treatment induces apoptosis and inhibits metastasis in human epithelial type 2 (HEp-2) human laryngeal epidermoid carcinoma cells $(5,6)$. However, the mechanism by which TCS exerts its antitumor effects remains to be fully elucidated. Although certain studies have reported that TCS irreversibly inactivates ribosomes and inhibits protein synthesis in carcinoma to inhibit malignant tumor proliferation $(7,8)$. Others have observed that TCS induces apoptosis in tumors either through caspase-3 activation or by the disruption of cytoskeletal configurations $(9,10)$. It is possible that the antitumor activity of TCS, demonstrated by the in vitro inhibition of cell viability, is mediated by multiple mechanisms, including cell cycle arrest and apoptosis. 
Mitogen-activated protein kinases (MAPKs) are signaling molecules, which convert extracellular stimuli into a wide range of cellular responses (8). c-Jun $\mathrm{N}$-terminal protein kinase (JNK) is an MAPK subfamily with three isoforms (JNK1, 2 and 3) and a splicing variant. JNK1 and JNK2 are ubiquitously expressed, whereas JNK3 is primarily expressed in neuronal and heart tissues (11). JNKs and p38 are activated by environmental and genotoxic stresses and are important in inflammation and tissue homeostasis through the control of cell proliferation, differentiation, survival and migration of specific cell types (8). The JNK inhibitor, CEP-11004, reduces the anti-HIV activity of TCS, suggesting that TCS may specifically target JNK (12). TCS has also been reported to suppress the elevation of p38 MAPK, impairing the viral replication in Vero cells or inhibit HeLa cell proliferation through suppression of the protein kinase c/MAPK signaling pathway $(13,14)$. These findings suggest that the MAPK family may be responsible for the antiviral activity of TCS (12).

In the present study, the mechanism by which TCS exerts antitumor activity in the HEp-2 and AMC-HN-8 human laryngeal epidermoid carcinoma cell lines was investigated by examining the potential role of JNK in inhibiting cell viability and inducing apoptosis in response to TCS treatment.

\section{Materials and methods}

Materials. TCS was purchased from the Jinshan Pharmaceutical Co, Ltd. (Shanghai, China). Cisplatin was obtained from the Jingang Pharmaceutical Co Ltd. (Nanjing, China). The HEp-2 and AMC-HN-8 human laryngeal epidermoid carcinoma cell lines were provided by the Cell Bank of the Chinese Institute of Biochemistry and Cell Biology (Shanghai, China). The cell counting kit- 8 (CCK-8) assay and Hochest33258 were purchased from Dojindo (Kumamoto, Japan). The JNK inhibitor, SP600125, was purchased from Sigma-Aldrich (St. Louis, MO, USA). The CytoTox 96 non-radioactive cytotoxicity assay was obtained from Promega Corportation (Madison, WI, USA). Polyclonal rabbit anti-human antibodies against caspase-3, caspase-9, JNK, phosphorylated (phospho)-JNK (Thr183/Tyr185), phospho-extracellular signal-regulated kinase (ERK)1/2 (Thr202/Tyr204) and phospho-p38 (Thr180/Tyr182) were obtained from Cell Signaling Technology, Inc. (Beverly, MA, USA).

Cell culture conditions. All the cells were maintained in RPMI-1640 medium, which was purchased from Gibco-BRL (Grand island, CA, USA) supplemented with 10\% heat-inactivated fetal bovine serum (FBS; Gibco-BRL), penicillin (100 units/ml; Beyotime, Jiangsu, China) and streptomycin $\left(100 \mu \mathrm{g} / \mathrm{ml}\right.$; Beyotime) in a $5 \% \mathrm{CO}_{2}$ incubator at $37^{\circ} \mathrm{C}$. For the present study, the cells were incubated in either the presence or absence of different concentrations of TCS $(1,5,9$ or $13 \mu \mathrm{g} / \mathrm{ml}$ ), with or without $3 \mu \mathrm{g} / \mathrm{ml}$ cisplatin for 5 days.

Cell viability and cell proliferation assays. The inhibitory effects of the various treatments on HEp-2 and AMC-HN-8 cell viability were determined by CCK- 8 assay. The cells, in the exponential growth phase, were seeded into 96-well plates with $100 \mu \mathrm{l}\left(1 \times 10^{4} / \mathrm{ml}\right)$ per well. Subsequently, different concentrations of TCS $(1,5,9$ and $13 \mu \mathrm{g} / \mathrm{ml})$ were added.
Each treatment was performed in triplicate wells and a control group consisting of cells grown in culture medium containing no drugs was included. The plates were placed in an incubator in a humidified atmosphere at $37^{\circ} \mathrm{C}$ for 5 days. At the end of the exposure, $10 \mu$ l CCK- 8 was added to each well and the plates were incubated at $37^{\circ} \mathrm{C}$ for $1 \mathrm{~h}$. The absorbance of each well was then measured using a standard enzyme-linked immunosorbant assay at 450 and $650 \mathrm{~nm}$ and the absorbance values were labeled A450 and A650, respectively. The inhibitory rate was calculated as follows: HEp-2 or AMC-HN-8 cells $(100 \%)=1-($ Atreat490 - Atreat 650)] / (Acontrol490 - Acontrol650) x100\% and the results were measured in triplicate. SPSS 16.0 software (SPSS, Inc., Chicago, IL, USA) was used to calculate the $50 \%$ inhibitory concentration for each group of drugs and the cell proliferation was analyzed by counting the number of cells with a hemocytometer (Hausser Scientific, Horsham, PA, USA) using trypan blue (Sangon Biotech, Shanghai, China) exclusion as the criterion for cell viability.

Cell necrosis assays. Following treatment of the HEp-2 and AMC-HN-8 cells with different concentrations of TCS (final concentrations of $1,5,9$ and $13 \mu \mathrm{g} / \mathrm{ml}$ ) for $48 \mathrm{~h}$, the culture supernatant was harvested by centrifugation at $670 \mathrm{x} g$ for $10 \mathrm{~min}$. The supernatant $(50 \mu \mathrm{l})$ from each well of the assay was transferred to the corresponding well of a flat-bottomed 96-well enzymatic assay plate with $50 \mu 1$ reconstituted substrate mix (CytoTox $96^{\circledR}$ non-radioactive cytotoxicity assay; Promega Corporation, Madison, WI, USA). The assay plate was then incubated at room temperature and protected from light for $30 \mathrm{~min}$. The absorbance of each well was then measured at $490 \mathrm{~nm}$ following the addition of $50 \mu \mathrm{l}$ stop solution (Promega Corportation).

Hoechst 33258 staining. The cells were cultured on cover slides and incubated in the presence of $5 \mu \mathrm{g} / \mathrm{ml} \mathrm{TCS}$ for $48 \mathrm{~h}$. Following fixation with $1 \%$ glutaraldehyde (Sangon Biotech) for $30 \mathrm{~min}$, the cells were stained with $10 \mu \mathrm{g} / \mathrm{ml}$ Hoechst 33258 at room temperature for $10 \mathrm{~min}$. For each cover slide, 1,500 cells were observed under a Leica fluorescence microscope (magnification, x200; model, Laser 355,375, Leica Microsystems, Wetzlar, Germany) and images were captured using a digital camera (Leica Microsystems). Apoptosis, a form of cell death, is characterized by morphological changes, including chromatin condensation and apoptotic body formation. The percentage of cells undergoing apoptosis was determined (15).

Annexin V/propodium iodide (PI) staining assay. The cells were treated either with different concentrations of TCS or $3 \mu \mathrm{g} / \mathrm{ml}$ cisplatin for $48 \mathrm{~h}$. The cells were then trypsinized, harvested by centrifugation at $536 \mathrm{x}$ g for $5 \mathrm{~min}$, washed twice and resuspended in $100 \mu \mathrm{l}$ binding buffer (eBioscience, San Diego, CA, USA). The cell density was adjusted to $1 \times 10^{5} / \mathrm{ml}$ and the cells were incubated with $5 \mu 1$ annexin V-fluorescein isothiocyanate (FITC) and $5 \mu \mathrm{l}$ PI for $15 \mathrm{~min}$ at room temperature. The samples were analyzed using a fluorescence-activated cell sorting (FACS)scan flow cytometer (Becton-Dickinson, New York, NY, USA). Early apoptosis and necrosis were determined as the percentage of annexin $\mathrm{V}$ positive /PI negative or the percentage of annexin $\mathrm{V}$ positive/PI positive cells. 
Analysis of cell cycle phase distribution by flow cytometry. The present study synchronized the cells in the G0-phase through serum deprivation prior to treatment. After 3 days culture in medium containing $5 \mu \mathrm{g} / \mathrm{ml}$ TCS, the HEp-2 and AMC-HN-8 cells were collected by trypsinization, washed with phosphate-buffered saline (PBS; Sangon Biotech, Shanghai, China) and fixed in ice-cold $70 \%$ ethanol for $24 \mathrm{~h}$. The cells were then stained with $1 \mathrm{ml}$ PI $(0.1 \mathrm{mg} / \mathrm{ml}$ with $0.1 \%$ Triton X-100; Sangon Biotech) and incubated in the dark for $30 \mathrm{~min}$. The samples were analyzed by flow cytometric analysis using FACSCalibur (Becton-Dickinson). PI is a highly water soluble, fluorescent compound that cannot pass through intact membranes and is generally excluded from viable cells. PI binds to DNA by intercalating between the bases in double-stranded nucleic acids in exposed nuclei (16).

Reverse transcription quantitative polymerase chain reaction (RT-qPCR) assays. The total RNA was extracted from the HEp-2 and AMC-HN-8 cells using aguanidium thiocyanate hot phenol-chloroform method (17). This total RNA (100 ng) was used for the synthesis of first-strand cDNA by RT in a reaction mixture $(20 \mu \mathrm{l})$ containing $5 \mu \mathrm{M}$ random hexamers, $2.5 \mu \mathrm{M}$ oligo (dT) primer and $0.1 \mu \mathrm{M}$ specific primer (Takara Bio, Inc., Shiga, Japan). The reaction was performed at $37{ }^{\circ} \mathrm{C}$ for $15 \mathrm{~min}$ and at $85^{\circ} \mathrm{C}$ for $5 \mathrm{sec}$.

The RT-qPCR reactions were performed using an ABI PRISM 7500 RT-qPCR system (Applied Biosystems, Foster City, CA, USA). For data analysis, the $2^{-\Delta \mathrm{CT}}$ (18) method was used to calculate the fold change. GADPH was considered to be unaffected by the treatment conditions in the present study and was used as a reference gene for normalization of the threshold cycle. The following primer sequences for the genes were used: p21, forward 5'-TGTCCGTCAGAACCCATGC-3' and reverse 5'-AAAGTCGAAGTTCCATCGCTC-3'; p27, forward 5'-ATCACAAACCCCTAGAGGGCA-3' and reverse 5'-GGG TCTGTAGTAGAACTCGGG-3'; Ki67, forward 5'-AGAAGA AGTGGTGCTTCGGAA-3' and reverse 5'-AGTTTGCGT GGCCTGTACTAA-3'; p53, forward 5'-ACAGCTTTGAGG TGCGTGTTT-3' and reverse 5'-CCCTTTCTTGCGGAGATT CTCT-3' and PCNA, forward 5'-ACACTAAGGGCCGAA GATAACG-3' and reverse 5'-CAGCATCTCCAATATGGC TGAG-3'. The following conditions were used: 1 cycle at $95^{\circ} \mathrm{C}$ for $30 \mathrm{sec}, 40$ cycles as $95^{\circ} \mathrm{C}$ for $5 \mathrm{sec}, 34$ seconds at $60^{\circ} \mathrm{C}, 1$ cycle at $95^{\circ}$ for $15 \mathrm{sec}, 60 \mathrm{sec}$ at $60^{\circ} \mathrm{C}$ and $15 \mathrm{sec}$ at $95^{\circ} \mathrm{C}$.

Western blot analysis. The whole cell extracts were prepared by directly dissolving the cells in $1 \mathrm{X}$ SDS loading buffer (Beyotime Institute of Biotechnology, Shanghai, China). Equal quantities $\left(1 \times 10^{5}\right.$ cells/lane) of protein were separated by $12 \%$ SDS-polyacrylamide gel electrophoresis (15\% SDS-polyacrylamide gel electrophoresis for caspase-9 and caspase-3), transferred onto polyvinylidene fluoride membranes (Millipore Corporation, Bedford, MA, USA) and inhibited at room temperature for $30 \mathrm{~min}$ with $5 \%$ non-fat milk in Tris-buffered saline containing Tween 20 (TBST; Sangon Biotech) containing $20 \mathrm{~mm}$ Tris- $\mathrm{HCl}$ (pH 7.6), $500 \mathrm{~mm} \mathrm{NaCl}$ and $0.1 \%$ (v/v) Tween 20. The blots were incubated overnight at $4^{\circ} \mathrm{C}$ with the following primary antibodies diluted in TBST buffer: JNK, phospho-JNK (Thr183/Tyr185), p38, phospho-p38 (Thr180/Tyr182), caspase-9 or caspase-3 primary antibodies
(1:5,000). Following washing with TBST, the membranes were incubated with horseradish peroxidase-conjugated goat anti-rabbit secondary antibodies (1:4,000; KPL, Gaithersburg, MD, USA) and were visualized using an enhanced chemiluminescence detection kit (Thermo Scientific, Inc., Fair Lawn, NJ, USA) according to the manufacturer's instructions.

Statistical analysis. SPSS 16.0 software (SPSS, Inc.) was used for data analysis. All data are expressed as the mean \pm standard deviation from at least two independent experiments. A two-sided Student's t-test was used to compare continuous variables between two groups. $\mathrm{P}<0.05$ was considered to indicate a statistically significant difference.

\section{Results}

TCS inhibits the viability of HEp-2 and AMC-HN-8 cells independently of necrosis. To validate the suppressive effect of TCS on cell viability, the HEp-2 and AMC-HN-8 cells were treated with a range of concentrations $(0-13 \mu \mathrm{g} / \mathrm{ml})$ of TCS for 5 days followed by CCK- 8 assay analysis. TCS inhibited the viability of the HEp-2 and AMC-HN- 8 cells in a doseand time-dependent manner (Fig. 1A and B). According to the slope of growth inhibition, the most significant effects of TCS were observed after 2 days of treatment. Lactate dehydrogenase $(\mathrm{LDH})$ is a stable cytosolic enzyme, which can be released during the necrosis process (19). However, no differences in LDH levels were observed in the culture supernatant between the day 2 experiment group and the control group ( $P>0.05)$, suggesting that the suppressive activity of TCS was independent of necrosis (Fig. 1C and D). LDH is released upon cell lysis; however, necrosis is characterized by cell swelling and rapid loss of membrane integrity, causing LDH to be released into the cell culture supernatant, which was assessed in the present study using a CytoTox $96^{\circledR}$ non-radioactive cytotoxicity assay (20). During apoptosis, cells undergo nuclear and cytoplasmic shrinkage, chromatin is partitioned into multiple fragments and the cells are fragmented into multiple membrane-surrounded apoptotic bodies, however the integrity of the cell membrane is retained during this process. Therefore, TCS significantly suppresses the viability of HEp-2 and AMC-HN-8 cells through apoptosis or another method that is independent of necrosis (15).

TCS induces apoptosis in HEp-2 and AMC-HN-8 cells. The HEp-2 and AMC-HN-8 cells were treated with TCS $(5 \mu \mathrm{g} / \mathrm{ml})$, cisplatin $(3 \mu \mathrm{g} / \mathrm{ml})$ or the two combined for 2 days followed by staining with Hoechst 33258. The morphological features of apoptosis, including the primary feature of apoptotic body formation, were then visualized by fluorescence microscopy (Fig. 2A and B). The results revealed significantly more apoptotic cells in the combination group compared with either the TCS- or cisplatin-only group when the total number of apoptotic cells were counted on a $1 \mathrm{~cm}^{2}$ cover slip $(\mathrm{P}<0.05$, supplemental Fig. 1). The apoptotic HEp-2 and AMC-HN-8 cells were also examined following treatment with different concentrations of TCS $(0-13 \mu \mathrm{g} / \mathrm{ml})$ for $48 \mathrm{~h}$ using flow cytometry. The lower left quadrant of each panel in Fig.2 indicated viable cells, which excluded PI and were negative for annexin V-FITC binding (Fig. 2C and D). The upper right 
A

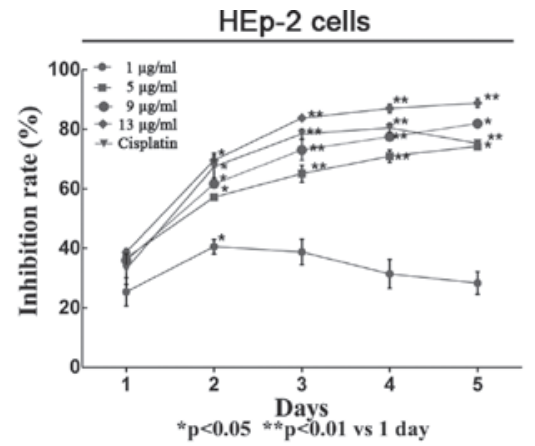

C

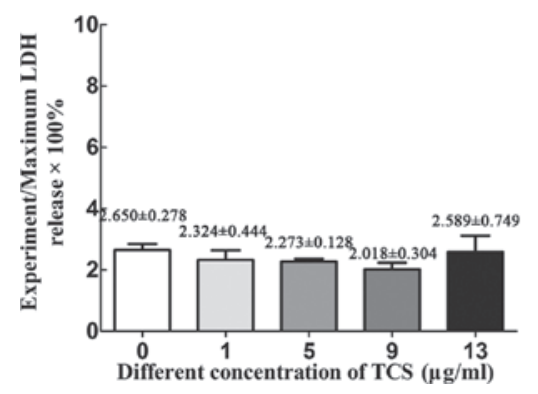

B

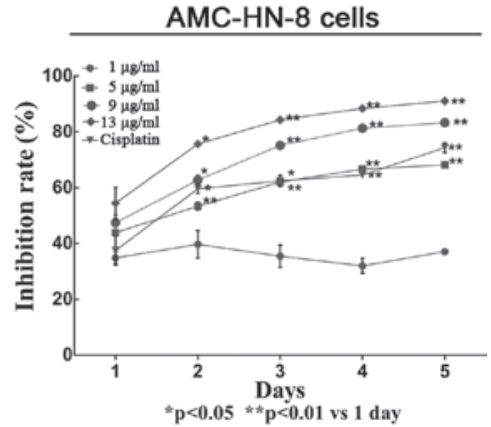

D

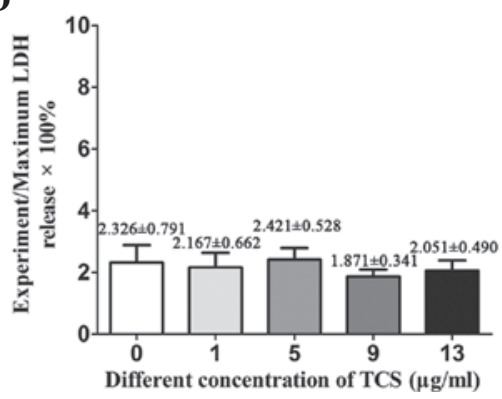

Figure 1. Inhibitory effects and cytotoxicity of TCS in (A and C) HEp-2 and (B and D) AMC-HN-8 cells. Cell viability was determined using a cell counting kit-8 assay. (A and B) Inhibition rate of the treated cells was expressed as a percentage relative to the corresponding control. (C and D) Culture supernatants from the 2 day experimental group were collected to determine the cytotoxicity of TCS. TCS significantly inhibited the cell viability of HEp-2 and AMC-HN-8 cells $\left({ }^{*} \mathrm{P}<0.05\right.$ and ${ }^{* *} \mathrm{P}<0.01$, vs. 1 day). Compared with the control, no significant differences were observed in the LDH levels in the culture supernatant among the experimental groups. TCS, trichosanthin; HEp-2, human epithelial type 2; LDH, lactate dehydrogenase.

quadrants indicated non-viable, necrotic cells, which were positive for annexin V-FITC binding and PI uptake (Fig. 2C and D). The percentage of annexin V-FITC positive/PI negative cells, which indicated cells with an exposed phospholipid and intact plasma membrane, increased between 1.53 and $13.4 \%$ in the HEp-2 group and between 3.14 and $22.4 \%$ in the AMC-HN-8 group in the presence of $0-13 \mu \mathrm{g} / \mathrm{ml} \mathrm{TCS}$ for $48 \mathrm{~h}$. Collectively, these data confirmed that TCS induced apoptosis in the HEp-2 and AMC-HN-8 human laryngeal epidermoid carcinoma cells in a dose-dependent manner. However, it remains to be elucidated whether $13 \mu \mathrm{g} / \mathrm{ml}$ TCS and $3 \mu \mathrm{g} / \mathrm{ml}$ cisplatin shared similar inhibitory effects on the HEp-2 cells $(69.64 \pm 3.1 \%$ and $67.38 \pm 5.0 \%$, respectively) and AMC-HN-8 cells $(75.66 \pm 4 \%$ and $59.58 \pm 3.3 \%$, respectively) on the second day (Fig. 1A and B). The cisplatin-induced apoptotic rate was markedly higher, suggesting that the increased suppressive effect of TCS on the HEp-2 and AMC-HN-8 cells was partly independent of apoptosis.

TCS induces cell cycle arrest in human laryngeal epidermoid carcinoma cells. To investigate the potential suppressive effects of TCS on the HEp-2 and AMC-HN-8 cells not caused by apoptosis, the cell cycle was analyzed. Cell cycle analysis indicated that culture with TCS for $48 \mathrm{~h}$ induced cell cycle arrest, as revealed by changes in the percentages of cells in each cell cycle sub-phase (Fig. 3A and B). After 3 days, the majority of the TCS-treated HEp-2 and AMC-HN-8 cells exhibited a prolonged S-phase (Fig. 3A). On the second day, the percentage of cells in the S-phase was significantly increased and the percentage of cells in the G1-phase was significantly decreased compared with the control ( $\mathrm{P}<0.01$; Fig. 3B). Based on this observation, it was hypothesized that TCS may impair DNA replication in the HEp-2 and AMC-HN-8 cells or may activate cyclin-dependent kinase (CDK) inhibitors (CKIs) to arrest the cells in the early S-phase. Consistent with this hypothesis, the cell proliferation assay indicated that TCS treatment resulted in a significant reduction in the number of growing cells compared with the untreated cells (Fig. 3C). To further determine the molecular mechanism underlying the TCS-induced S-phase cell cycle arrest, RT-qPCR was performed. Cell cycle-regulatory genes, including $\mathrm{p} 27^{\mathrm{kip} 1}$ and p21 $1^{\text {Waff } / \text { ipl } 1}$, were examined by RT-qPCR in the cells pre-treated with $5 \mu \mathrm{g} / \mathrm{ml}$ TCS for $48 \mathrm{~h}$. As expected, the mRNA expression levels of p $27^{\mathrm{kipl}}$ and $\mathrm{p} 21^{\text {Wafl/cipl }}$ were significantly upregulated following TCS stimulation for $48 \mathrm{~h}$. The expression levels of the $\mathrm{p} 21^{\text {Wafl/cip1 }}$ family CKIs, $\mathrm{p} 21^{\text {Wafl/cip1 }}$ and p2 $7^{\text {kipl }}$, are important in the precise regulation of CDK activity, which is essential for normal cell cycle progression (21).

JNK is activated by TCS treatment. The activation of JNK, which occurs through phosphorylation at Thr183 and Tyr185, was investigated by western blot analysis of the HEp-2 and AMC-HN-8 cells following treatment with different concentrations of TCS for different durations. Compared with the control group, the increased concentrations of TCS and the increased treatment durations caused upregulation in the levels of 54/46 kDa phospho-JNK fragments (Fig. 4). However, no significant differences were observed in the protein levels of JNK between the different experimental groups. In these experiments, $\beta$ actin was used as a control to confirm equal loading. JNK/MAPK is important in cell proliferation, differentiation and apoptosis and the present study hypothesized that the antitumor activity of TCS may be mediated by the activation of JNK/MAPK.

Inhibitory effects on the cell viability and apoptotic activity of TCS is suppressed by the SP600125 JNK/MAPK inhibitor. In general, TCS treatment reduced the viability of the HEp-2 and 
A
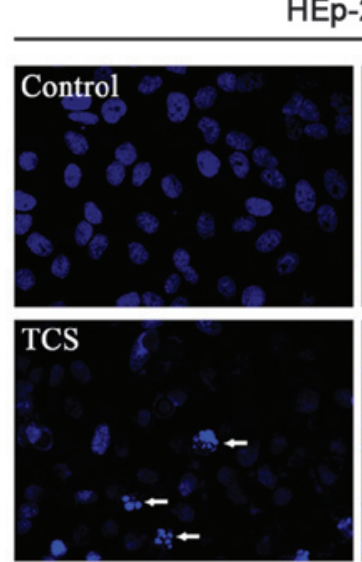

C

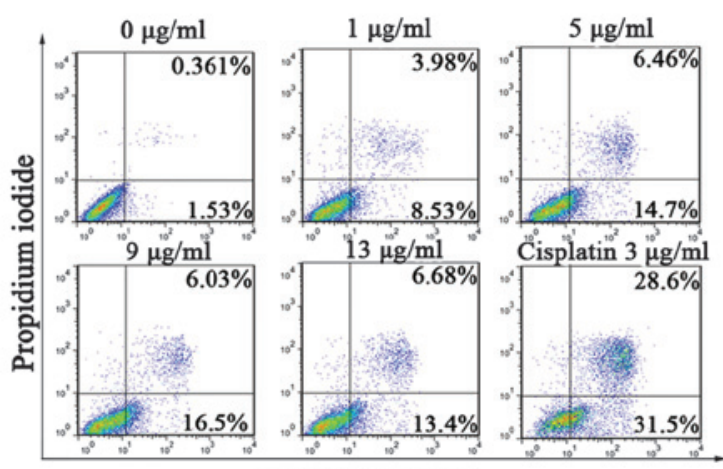

B
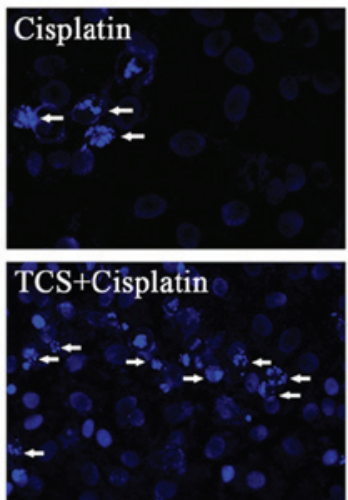

FITC-Annexin V

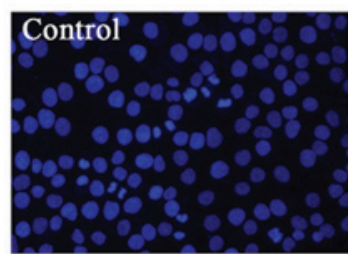

AMC-HN-8 Cells
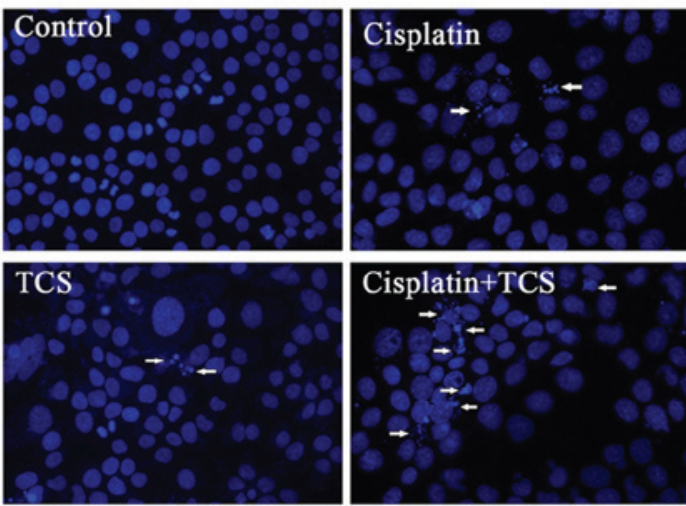

D

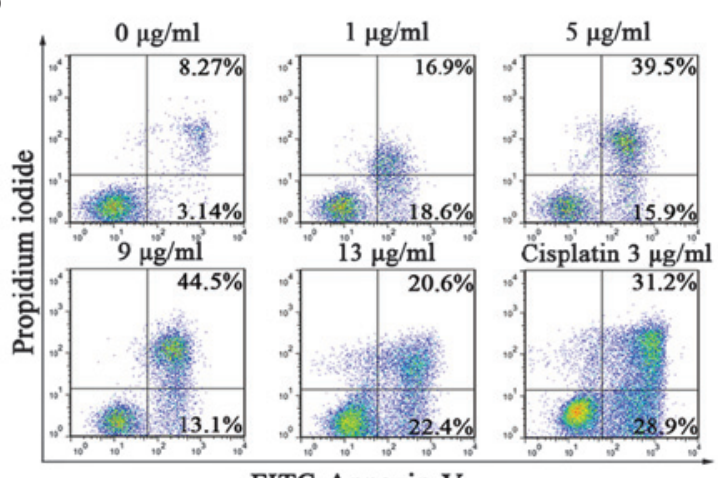

FITC-Annexin V

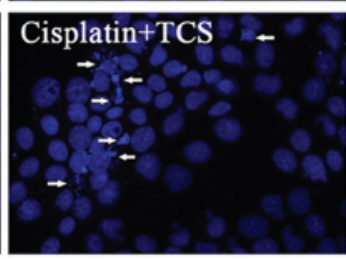

$\mu \mathrm{g} / \mathrm{ml}$

Figure 2. TCS-induced HEp-2 and AMC-HN-8 cell apoptosis. The HEp-2 and AMC-HN-8 cells were exposed to $5 \mu \mathrm{g} / \mathrm{ml}$ TCS in the presence or absence of $3 \mu \mathrm{g} / \mathrm{ml}$ cisplatin. (A and B) Apoptotic fragments of nuclei (white arrows) were detected by Hoechst 33258 staining. (C and D) Annexin V-FITC/PI contour diagram from flow cytometric analysis of the HEp-2 and AMC-HN-8 cells treated for $48 \mathrm{~h}$ with different concentrations of TCS or $3 \mu \mathrm{g} / \mathrm{ml}$ cisplatin. The upper right quadrants contain the non-viable or necrotic cells, which were positive for Annexin V-FITC binding and PI uptake. The lower right quadrants represent the apoptotic cells, which were Annexin V-FITC-positive and PI-negative, demonstrating cytoplasmic membrane integrity. TCS, trichosanthin; HEp-2, human epithelial type 2; FITC, fluorescein isothiocyanate; PI, propidium iodide.

A

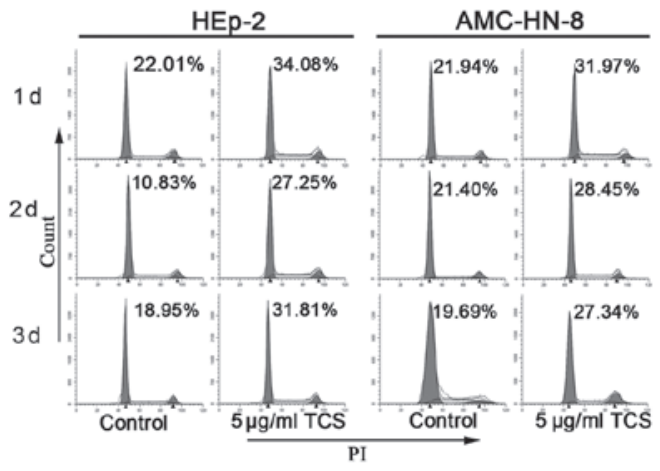

C

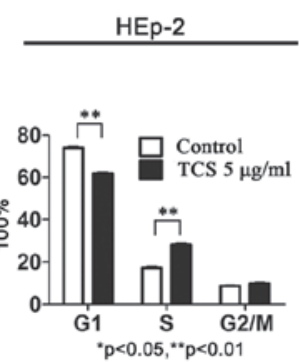

AMC-HN-8

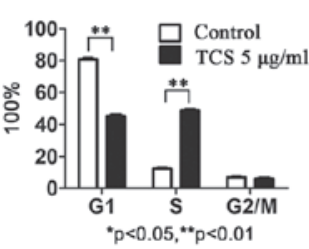

B
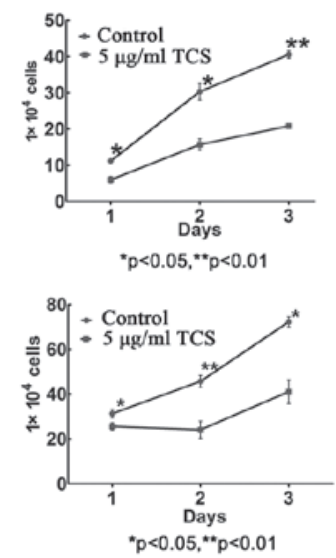

D

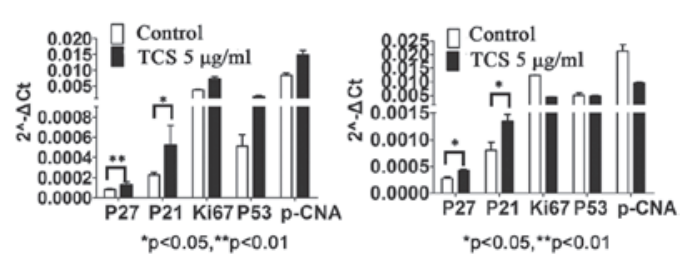

Figure 3. TCS causes cell cycle arrest in the HEp-2 and AMC-HN-8 cells. The cells were seeded into six-well plates containing RPMI-1640 and $10 \%$ fetal bovine serum and were harvested after 3 days. Cell proliferation and cell cycle were analyzed using an optical microscope and flow cytometic analysis. The genes involved in cell cycle progression were investigated using RT-qPCR. (A and B) Compared with the control, the percentage of cells in the S-phase increased daily in the cells that had been pre-treated with $5 \mu \mathrm{g} / \mathrm{ml}$ TCS. On the second day, the percentage of cells in the S-phase increased significantly (P<0.05). (C) A cell proliferation assay indicated that TCS caused a significant reduction in the number of growing cells compared with the untreated cells (P<0.05). (D) RT-qPCR analysis of the expression of p21, p27 and other cell cycle-associated genes in the HEp-2 and AMC-HN-8 cells. TCS, trichosanthin; HEp-2, human epithelial type 2; PI, propidium iodide; RT-qPCR, reverse transcription quantitative polymerase chain reaction. ${ }^{*} \mathrm{P}<0.05$ and ${ }^{*} \mathrm{P}<0.01$, compared with control. 


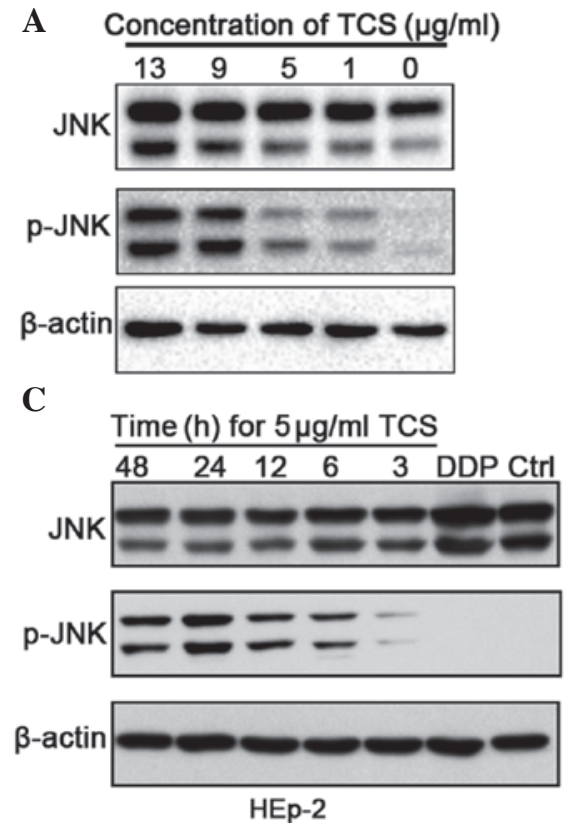

B Concentration of TCS $(\mu \mathrm{g} / \mathrm{ml})$

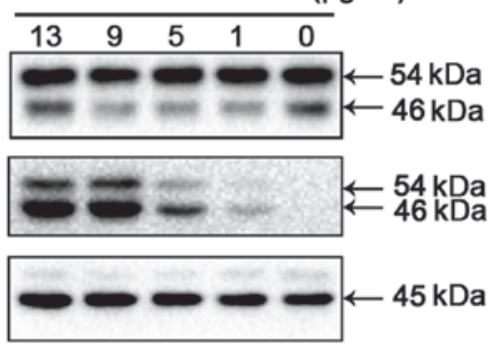

D

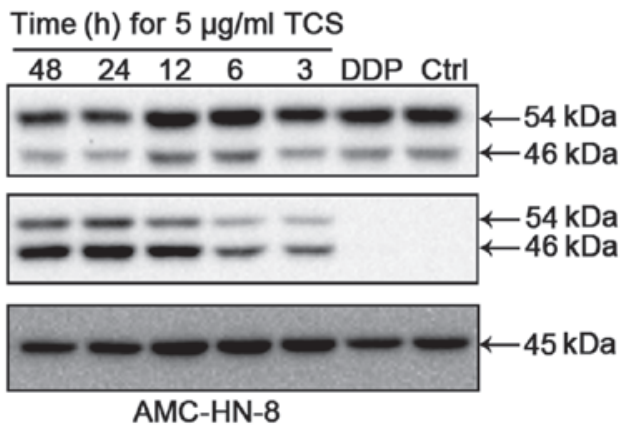

Figure 4. TCS induces JNK activation in a dose- and time-dependent manner. The HEp-2 and AMC-HN-8 cells, which had been treated with $5 \mu \mathrm{g} / \mathrm{ml}$ TCS, were harvested at different time points, while two other groups were treated with different concentrations of TCS and harvested after $48 \mathrm{~h}$. The levels of JNK/MAPK and p-JNK/MAPK were then assayed by western blot analysis. $\beta$-actin was used as a loading control for equal total cell numbers. TCS, trichosanthin; JNK, c-Jun N-terminal protein kinase; MAPK, mitogen-activated protein kinase; p-, phosphorylated-; HEp-2, human epithelial type 2 DDP, cisplatin.

AMC-HN-8 cells, as discussed previously. Compared with HEp-2 cells treated with $5 \mu \mathrm{g} / \mathrm{ml}$ TCS alone, co-administration with SP600125 and TCS increased the cell viability between $52.2 \pm 9.3 \%$ and $63.58 \pm 3.5 \%$, respectively, and suppressed the inhibitory effect of TCS on the HEp-2 cells. This result was also observed in the AMC-HN-8 cells. Increasing the concentration of SP600125 caused further increases in cell viability, however, the magnitude of the effect differed (Fig. 5A and B). In addition, SP600125 decreased the apoptotic rate (Fig.5; upper right + lower right quadrants) of the HEp-2 cells between $13.56 \%$ and $4.67 \%$ and AMC-HN-8 cells between 21.8 and $5.67 \%$. To investigate the involvement of various caspase pathways during TCS-induced apoptosis, western blot analysis of the TCS-treated cells was performed using specific antibodies against caspase- 3 and caspase- 9 . The cells were treated with $5 \mu \mathrm{g} / \mathrm{ml}$ TCS and different concentrations of SP600125 $(0-10 \mu \mathrm{M})$ for $48 \mathrm{~h}$ followed by protein extract preparation and SDS-PAGE fractionation. SP600125 is a known JNK inhibitor, which inhibits JNK/MAPK phosphorylation (22), however, SP600125 did not affect p38/MAPK or ERK/MAPK phosphorylation (Fig. 5D and E). Furthermore, the TCS-induced caspase-9 and caspase-3 cleavage was inhibited by SP600125 in a dose-dependent manner. These results suggested that JNK may be important in TCS-induced apoptosis and the inhibition of cell viability.

\section{Discussion}

In the present study, TCS inhibited the viability of HEp-2 and AMC-HN-8 human laryngeal epidermoid carcinoma cell lines independently of necrosis. Furthermore, flow cytometric analysis using annexin V/PI demonstrated that TCS induced early and late apoptosis in the HEp-2 and AMC-HN-8 cells in a dose-dependent manner. In accordance with this observation, stereotypical apoptotic features were detected (Fig. 2A and B). In previous studies, a concentration of $\sim 100 \mu \mathrm{g} / \mathrm{ml}$ TCS has been used to investigate its antitumor activity. Apoptosis is considered to be the primary antitumor mechanism of TCS $(9$, $10,23)$. However, high concentrations of TCS are cytotoxic, not only to tumor cells, but also to normal cells, suggesting that TCS is unsuitable for in vivo experiments. By contrast, lower concentrations of TCS $(1,5,9$ and $13 \mu \mathrm{g} / \mathrm{ml})$ were used in the present study and, although TCS-mediated apoptosis was less evident compared with that following $3 \mu \mathrm{g} / \mathrm{ml}$ cisplatin treatment, for which the apoptosis mechanism has been clearly demonstrated, TCS did inhibit HEp-2 and AMC-HN-8 cell growth (CCK-8; Fig. 1A). Thus, a low concentration of TCS can be used in combination chemotherapy regimens with other cytotoxic drugs.

In the present study, the inhibitory effect of $13 \mu \mathrm{g} / \mathrm{ml}$ TCS on the viability of the HEp-2 and AMC-HN-8 cells was not lower than that of $3 \mu \mathrm{g} / \mathrm{ml}$ cisplatin, which is an important chemotherapeutic agent for head and neck squamous cell carcinoma (24). However, the apoptotic rate caused by $3 \mu \mathrm{g} / \mathrm{ml}$ cisplatin was higher compared with that caused by $13 \mu \mathrm{g} / \mathrm{ml}$ TCS (Fig. 2C and D). This observation suggested that, in addition to apoptosis, TCS may inhibit cell viability through other mechanisms. Following treatment with $5 \mu \mathrm{g} / \mathrm{ml}$ TCS for 3 days, the cells were stained with a trypan blue solution and counted using a hemocytometer. The cell proliferation assay indicated that TCS caused a significant reduction in the number of growing cells compared with the untreated cells $(\mathrm{P}<0.05)$. Consistent with this result, TCS treatment induced cell cycle arrest as changes were observed in the percentage of cells in S-phase. In the cells pretreated with $5 \mu \mathrm{g} / \mathrm{ml} \mathrm{TCS}$ for 2 days, the percentage of cells in the S-phase was significantly increased compared with the control (Fig. 3A and C). Similarly, the important CKIs, $\mathrm{p} 21^{\text {Wafl } / \text { ipl } 1}$ and $\mathrm{p} 27^{\mathrm{kip} 1}$, were prominently upregulated following 

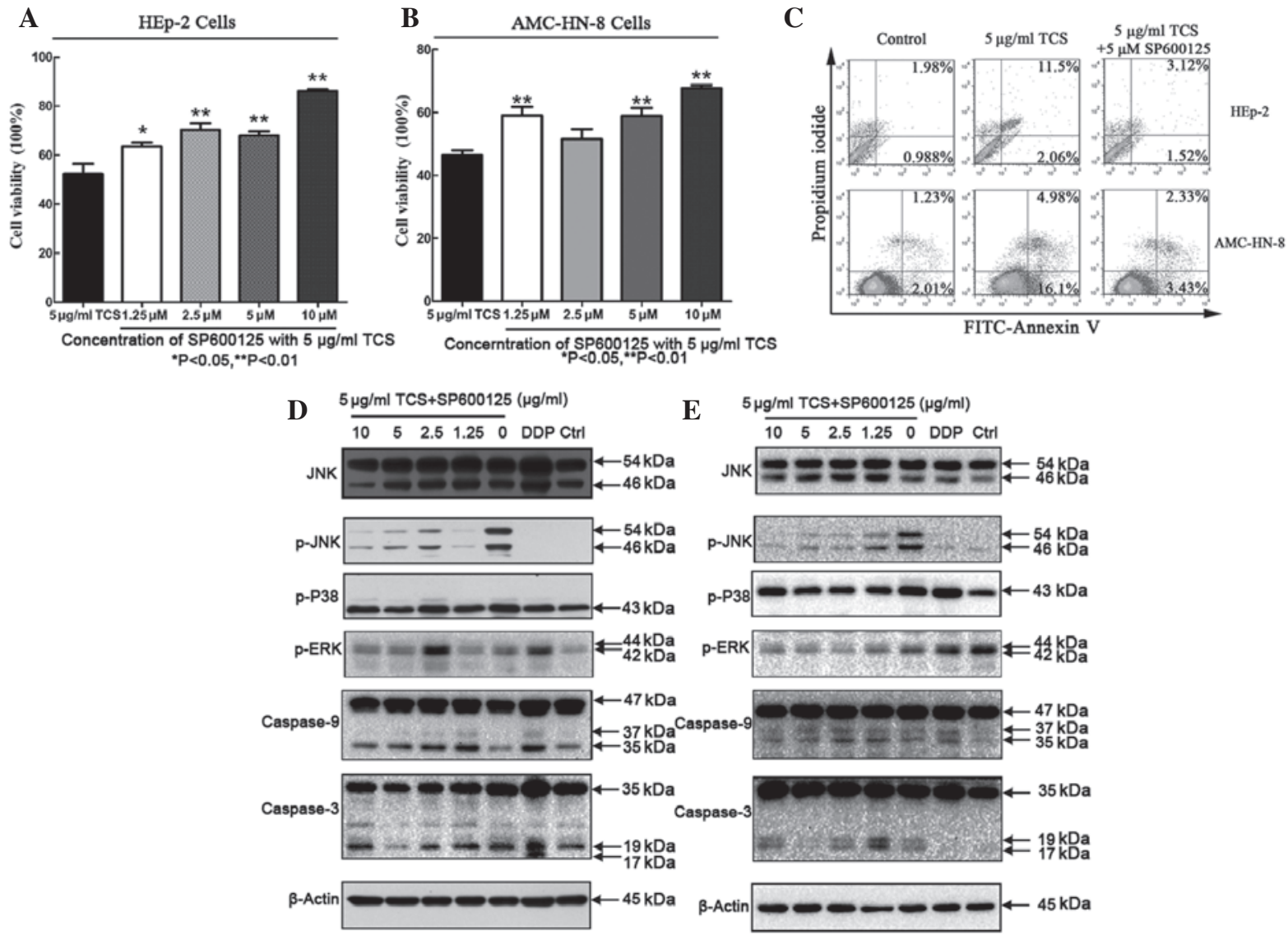

Figure 5. Cell growth inhibitory and apoptotic activities of TCS can be suppressed by SP600125. (A, B and C) HEp-2 and AMC-HN-8 cells were treated with $5 \mu \mathrm{g} / \mathrm{ml}$ TCS and different concentrations of SP600125, a JNK/MAPK inhibitor for 48 h. A cell counting kit-8 assay and flow cytometric analysis were performed to detect the growth inhibition and apoptotic rate among the experimental groups. The experiment was repeated three times. The results are expressed as the mean \pm standard deviation. Statistical analyses of the data was performed using Student's t-test and ** $\mathrm{P}<0.01$. SP600125 inhibited the TCS-induced activation of the apoptosis-associated proteins caspase-3 and caspase-9 in the (D) HEp-2 and (E) AMC-HN-8 cells. SP600125 decreased the levels of p-JNK in a dose-dependent manner, but did not affect p-p38/MAPK or p-ERK/MAPK activation. TCS, trichosanthin; HEp-2, human epithelial type 2; JNK, c-Jun N-terminal protein kinase; MAPK, mitogen-activated protein kinase; ERK, extracellular signal-regulated kinase; p-, phosphorylated-; FITC, fluorescein isothiocyanate; PI, propidium iodide; DDP, cisplatin.

TCS stimulation for $48 \mathrm{~h}$ (Fig. 3D). The findings of the present study and those of a previous study supported the hypothesis that treatment of uninfected HEp-2 cells with TCS prolongs the S-phase (6). The present study hypothesized that TCS may impair DNA replication through the induction of DNA damage. The DNA damage caused by TCS may be detected by the G2 checkpoint, which prevents cells from entering mitosis and results in S-phase or G2/M-phase arrest to provide time for the repair or initiation of the cell death pathway (25). However, the precise mechanism by which TCS induces S-phase arrest requires further investigation.

In the present study, a low concentration of TCS led to activation of the phospho-JNK in the HEp-2 and AMC-HN-8 cells in a dose- and time-dependent manner (Fig. 4A and B). JNK activation leads to the phosphorylation of cytoplasmic and nuclear targets, including the AP-1 transcription factor Jun and cell cycle regulators, including Cdc25, Aurora B and Cdh1, involved in modulating cell cycle, cell growth and cell death (26). Therefore, the antitumor activity of TCS may be associated with its activity in activating the JNK/MAPK pathway. SP600125, a known JNK inhibitor, specifically inhibited phospho-JNK activation in a dose-dependent manner without affecting other MAPK family members, including
phospho-ERK or phospho-p38 (Fig. 4D and E). Compared with $5 \mu \mathrm{g} / \mathrm{ml}$ TCS alone, the cell viability was significantly increased following addition of different concentrations of SP600125 to the culture medium. In addition, the protein levels of caspase- 3 and caspase- 9 protein, key cysteine proteases that are essential for apoptosis in eukaryotic cells (15), were downregulated by SP600125 in a dose-dependent manner. Caspase- 3 activation has been detected in several TCS-treated tumor cell lines, including HL-60, K562, HeLa and choriocarcinoma cells (30). Caspase-9 is the primary executor of the mitochondrial apoptoti pathway. Inhibition of caspase-9 with z-LEHD-FMK inhibits the cellular apoptotic processes induced by TCS, suggesting that the caspase-9-mediated mitochondrial pathway is involved in TCS-induced apoptosis (2). As the cytoplasmic injection of cytochrome c rescues the apoptotic defects of JNK-deficient fibroblasts, the pro-apoptotic functions of JNK may be mediated through the mitochondrial pathway (8). SP600125-mediated inhibition of the TCS-induced JNK pathway activation may reduce the ability of TCS to inhibit cell viability and induce apoptosis in the HEp-2 and AMC-HN-8 cells. The inhibition of cell viability and the apoptotic effect of TCS appear to be associated with phospho-JNK activation. 
The present study demonstrated that low concentrations of TCS, compared with the higher concentrations of TCS used in previous studies $(10,23,31)$ assessing antitumor activity suppressed human laryngeal epidermoid carcinoma cell viability and induced apoptosis via the induction of JNK pathway activation. The TCS-induced S-phase cell cycle arrest was partially attributed to the ability of TCS to inhibit cell viability. Therefore, TCS treatment offers a potential novel chemotherapy regimen for laryngocarcinoma, which can be used with other cytotoxic drugs in combination chemotherapy regimens.

\section{Acknowledgements}

This study was supported by the National Natural Science Foundation of China (nos. 30972691 and 30801283), the Technology Project of Shanghai (nos. 11JC1410802, 09QA1401000 and 10QA1405900) and Shanghai's Health System of Talents Training Plan (nos. XYQ2011055 and XYQ2011015).

\section{References}

1. Shaw PC, Chan WL, Yeung HW and Ng TB: Minireview: trichosanthin - a protein with multiple pharmacological properties. Life Sci 55: 253-262, 1994.

2. Li M, Li X and Li JC: Possible mechanisms of trichosanthin-induced apoptosis of tumor cells. Anat Rec (Hoboken) 293: 986-992, 2010.

3. Tsao SW, Ng TB and Yeung HW: Toxicities of trichosanthin and alpha-momorcharin, abortifacient proteins from Chinese medicinal plants, on cultured tumor cell lines. Toxicon 28: 1183-1192, 1990.

4. Fang EF, Ng TB, Shaw PC and Wong RN: Recent progress in medicinal investigations on trichosanthin and other ribosome inactivating proteins from the plant genus Trichosanthes. Curr Med Chem 18: 4410-4417, 2011.

5. He D, Yau K, He X, et al: Conversion of trichosanthin-induced CD95 (Fas) type I into type II apoptotic signaling during Herpes simplex virus infection. Mol Immunol 48: 2000-2008, 2011.

6 . He D, Zheng Y and Tam S: The anti-herpetic activity of trichosanthin via the nuclear factor-kappaB and p53 pathways. Life Sci 90: 673-681, 2012.

7. Sha O, Yew DT, Ng TB, Yuan L and Kwong WH: Different in vitro toxicities of structurally similar type I ribosome-inactivating proteins (RIPs). Toxicol In Vitro 24: 1176-1182, 2010.

8. Wagner EF and Nebreda AR: Signal integration by JNK and p38 MAPK pathways in cancer development. Nat Rev Cancer 9: 537-549, 2009.

9. Wang P, Xu J and Zhang C: CREB, a possible upstream regulator of Bcl-2 in trichosanthin-induced HeLa cell apoptosis. Mol Biol Rep 37: 1891-1896, 2010.

10. Wang P and Li JC: Trichosanthin-induced specific changes of cytoskeleton configuration were associated with the decreased expression level of actin and tubulin genes in apoptotic Hela cells. Life Sci 81: 1130-1140, 2007.
11. Liu J and Lin A: Role of JNK activation in apoptosis: a double-edged sword. Cell Res 15: 36-42, 2005.

12. Ouyang DY, Chan H, Wang YY, et al: An inhibitor of c-Jun N-terminal kinases (CEP-11004) counteracts the anti-HIV-1 action of trichosanthin. Biochem Biophys Res Commun 339: 25-29, 2006.

13. Huang H, Chan H, Wang YY, et al: Trichosanthin suppresses the elevation of p38 MAPK, and Bcl-2 induced by HSV-1 infection in Vero cells. Life Sci 79: 1287-1292, 2006.

14. Wang P, Chen LL, Yan H and Li JC: Trichosanthin suppresses HeLa cell proliferation through inhibition of the PKC/MAPK signaling pathway. Cell Biol Toxicol 25: 479-488, 2009.

15. Kanduc D, Mittelman A, Serpico R, et al: Cell death: apoptosis versus necrosis (review). Int J Oncol 21: 165-170, 2002.

16. Gao LL, Feng L, Yao ST, et al: Molecular mechanisms of celery seed extract induced apoptosis via s phase cell cycle arrest in the BGC-823 human stomach cancer cell line. Asian Pac J Cancer Prev 12: 2601-2606, 2011.

17. Chirgwin JM, Przybyla AE, MacDonald RJ and Rutter WJ: Isolation of biologically active ribonucleic acid from sources enriched in ribonuclease. Biochemistry 18: 5294-5299, 1979.

18. Perez IC, Le Guiner C, Ni W, Lyles J, Moullier P and Snyder RO: PCR-based detection of gene transfer vectors: application to gene doping surveillance. Anal Bioanal Chem 405: 9641-9653, 2013.

19. Korzeniewski $C$ and Callewaert DM: An enzyme-release assay for natural cytotoxicity. J Immunol Methods 64: 313-320, 1983.

20. Decker T and Lohmann-Matthes ML: A quick and simple method for the quantitation of lactate dehydrogenase release in measurements of cellular cytotoxicity and tumor necrosis factor (TNF) activity. J Immunol Methods 115: 61-69, 1988.

21. Lu $\mathrm{Z}$ and Hunter T: Ubiquitylation and proteasomal degradation of the p21(Cip1), p27(Kip1) and p57(Kip2) CDK inhibitors. Cell Cycle 9: 2342-2352, 2010.

22. Bennett BL, Sasaki DT, Murray BW, et al: SP600125, an anthrapyrazolone inhibitor of Jun N-terminal kinase. Proc Natl Acad Sci USA 98: 13681-13686, 2001.

23. Xu J, Gao DF, Yan GL and Fan JM: Induced apoptotic action of recombinant trichosanthin in human stomach adenocarcinoma MCG803 cells. Mol Biol Rep 36: 1559-1564, 2009.

24. Lefebvre JL: Candidates for larynx preservation: the next step? Oncologist 15 (Suppl 3): 30-32, 2010.

25. Chen T, Stephens PA, Middleton FK and Curtin NJ: Targeting the $\mathrm{S}$ and $\mathrm{G} 2$ checkpoint to treat cancer. Drug Discov Today 17: 194-202, 2012.

26. Miotto B and Struhl K: JNK1 phosphorylation of Cdt1 inhibits recruitment of $\mathrm{HBO} 1$ histone acetylase and blocks replication licensing in response to stress. Mol Cell 44: 62-71, 2011.

27. Li J, Xia X, Nie H, Smith MA and Zhu X: PKC inhibition is involved in trichosanthin-induced apoptosis in human chronic myeloid leukemia cell line K562. Biochim Biophys Acta 1770: 63-70, 2007.

28. Li J, Xia X, Ke Y, et al: Trichosanthin induced apoptosis in HL-60 cells via mitochondrial and endoplasmic reticulum stress signaling pathways. Biochim Biophys Acta 1770: 1169-1180, 2007.

29. Wang P, Yan H and Li JC: CREB-mediated Bcl-2 expression in trichosanthin-induced Hela cell apoptosis. Biochem Biophys Res Commun 363: 101-105, 2007.

30. Zhang C, Gong Y, Ma H, et al: Reactive oxygen species involved in trichosanthin-induced apoptosis of human choriocarcinoma cells. Biochem J 355: 653-661, 2001.

31. Li M, Chen F, Liu CP, et al: Dexamethasone enhances trichosanthin-induced apoptosis in the HepG2 hepatoma cell line. Life Sci 86: 10-16, 2010. 